\title{
Experimental Research and Analysis of Vortex Excited Vibration Suppression of Spiral Stripe Strake
}

\author{
Zhongguo Yang* \\ Heilongjiang Bayi Agricultural University College of Engineering, Daqing 163319, China
}

\begin{abstract}
This paper carries out the experimental research and analysis on the vortex-excited vibration suppression effect of the spiral stripe strake via the laser particle velocimeter (PIV) under vortex speed $U=0.6 \mathrm{~m} / \mathrm{s}$ and attack angle $\alpha=300$, and discusses the VIV suppression mechanism of the spiral stripe strake by using the numerical simulation of the computational fluid dynamics (CFD) in order to objectively further know inherent mechanism of VIV, further optimize parameters of the spiral stripe strake, and provide references for theoretical research in future.
\end{abstract}

Keywords: Fluid dynamics, PIV, Spiral strike strake, Vortex vibration, Laser particle velocimeter, Computational fluid dynamics.

\section{THEORETICAL FOUNDATION AND MODEL OF PIV VELOCITY EXPERIMENT}

References on measurement of the wake flow field of the smooth column and spiral stripe column by using the laser particle velocity measurement system (PIV) are few, so the PIV measurement technology is used to study wake flow field of the spiral stripe strake column and smooth column with different spiral heights, discuss influences of the spiral strike strake on the vortex structure around the column and vortex street falling pattern, and perform CFD computing and analysis in order to further reflect the formation mechanism of the vortex-excited vibration suppression of the spiral stripe strake.

\subsection{Experimental Theory Foundation}

The control equation in the computing fluid dynamics involves many complicated partial differential equation. When the computing fluid dynamics is used to perform numerical simulation for some actual problems, a proper algorithm should be selected. Generally, a proper algorithm will improve simulation efficiency and correctness. With the development of computing method and computing technology, many complicated engineering problems can be implemented on the computer by using the area-discretized numerical mode. The frequent discretization methods include [1, 2], finite differential method, finite element method, finite volume method and boundary element method.

\subsubsection{Finite Differential Method}

Generation and evolvement of the finite differential method is early and mature and it is one of the most typical methods in numerical parsing. It replaces old whole solution area with a series of differential grids and then replaces these derivatives of partial differential equations with the

\footnotetext{
*Address correspondence to this author at the Heilongjiang Bayi Agricultural University College of Engineering, Daqing 163319, China; Tel: +8613820198716; E-mail: yangzhongguo@163.com
}

difference quotient, so the differential equation with several unknown parameters can be derived from these differential grids. Now the most fundamental differential expressions include one-order forward differential and one-order backward differential with one-order computing precision, and one-order center differential and two-order center differential with two-order computing precision. The finite differential method is extensively applied in solution of the parabola and double curve problem.

\subsubsection{Finite Element Method}

The finite element method indicates to divide one continuous solution domain into many differential units, then construct interpolation functions on these micro units, next apply the extreme principle to transform the engineering control equation to finite element equation on all micro units, and finally substitute the boundary conditions to solve this equation and get the algebra function values of different nodes. Generally, the finite element method is mainly used to solve the ellipse problem.

\subsubsection{Finite Volume Method}

The finite volume method indicates to divide the whole computing area into many micro grids, then ensure one different micro control body around each grid node, and next get a group of discrete equations on each micro control body. The basic idea of the finite volume method is to integrate the discrete and the sub-domain method. The discrete equation obtained by using the finite volume method requires that any control collective meets the integral conservation of the dependent variables, so the whole computing area also meets the integral conservation of the dependent variables, which shows excellence of the finite volume method.

\subsubsection{Boundary Element Method}

The boundary element method is to transform the differential equation of the described physical problem as the boundary integral equation based on the discretization method. The basic idea is to discretize the solution equation at the boundary of the solution domain and perform 
numerical computing. The basic numerical values and some integral computing of physical problems are used inside the solution domain, so the boundary element method includes half analysis and half numerical method.

The computing fluid dynamics software belongs to ANSYS simulation software CFX. For irregular grid used in this paper, the CFX used in the partial fluid numerical simulation is computed based on the finite volume method.

\subsection{Experimental Model [3-7]}

The open sink of the experimental sink is $6 \mathrm{~m}$ long. The observation section is $0.3 \times 0.4$ (width $\times$ height). Two steel tubes are placed respectively (with the spiral stripe cylinder and smooth cylinder) and fixed horizontally on the middle plane of the test area. To reduce the vortex degree of the incoming flow to most extent, the sink is equipped with the vortex elimination section and drilling steel plate and cellular shrinkage screen. The final test value of the vortex degree of the incoming flow is $2 \%$.

The LaVision PIV is used to measure the fluid field, which not only meets big observation area, but also considers the fluid field resolution. The observation area selected in this experiment is $125 \mathrm{~mm} \times 95 \mathrm{~mm}$. The laser system is $125 \mathrm{~mm} \times 95 \mathrm{~mm}$ laser (energy is $120 \mathrm{Mj}$ per pulse and the duration is $5 \mathrm{~ns}$ ). The camera is 12-bit CCD camera. The resolution is $1.6 \mathrm{~K} \times 1.2 \mathrm{~K}$ and the frame rate is $15 \mathrm{~Hz}$. The image processing includes two aspects. The initial grid is $64 \times 64$ pixels and gradually decreases to $32 \times 32$. The pixel overlapping ratio is $50 \%$, therefore, now the image resolution is set as $1.25 \mathrm{~mm} \times 1.25 \mathrm{~mm}$. Generally $1050-$ frame instantaneous fluid field can get a reasonable statistically converged fluid field. Other parameters include tracking particle size (about 3 pixels) and particle density (about 10-30 particles per $\mathrm{mm}^{2}$ ). These values can be optimized via the repeated test. Therefore, the diameter of the hollow glass ball is $10 \sim 15 \mu \mathrm{m}$ and the glass balls are sown inside the fluid as the tracking particles. The proportion is 1.05-1.15. The delay between the double pulses is set as $1000 \mu \mathrm{s}, 2000 \mu \mathrm{s}$ and $3000 \mu \mathrm{s}$, which correspond to the different test fluid speed $U=0.2 \mathrm{~m} / \mathrm{s}, 0.4 \mathrm{~m} / \mathrm{s}$ and $0.6 \mathrm{~m} / \mathrm{s}$ respectively.

The diameter $\mathrm{D}$ of the smooth cylinder in the wind tunnel is $12 \mathrm{~mm}$ and the length is $300 \mathrm{~m}$ (be equal to the width of the sink). The aspect ratio is 25 . The Fig. (1) indicates that 3screw head spiral stripe strake cylinder includes 3 thin strakes and is wound as the spiral. The strake helical pitch $\mathrm{P}$ is $25 \mathrm{D}$. The height $\mathrm{h}$ of the spiral strike is $0.1 \mathrm{D}$ and $0.2 \mathrm{D}$. The section parameters of the spiral stripe are described as follows: Three spiral stripes are equably distributed on the section. The included angle is $120^{\circ}$. The spiral stripe is $2 \mathrm{~mm}$ wide (Fig. 2). The Reynolds number based on the smooth cylinder $(\mathrm{Re}=\mathrm{UD} / \mathrm{v}, \mathrm{v}$ is the power viscosity coefficient of the water) is 2400,4800 and 7200 . To observe the vortex falling in the wing extension direction, PIV measures the instantaneous wake flow field under different attack angle $\alpha$.

To better understand suppression principle of spiral stripe strake on VIV, this paper performs numerical simulation for CFD. The geometric size of the numerical model and physical experimental model are same (1:1). The Fig. (3) gives the model and surface grid diagram of 3-spiral strike strake in the numerical simulation computing.

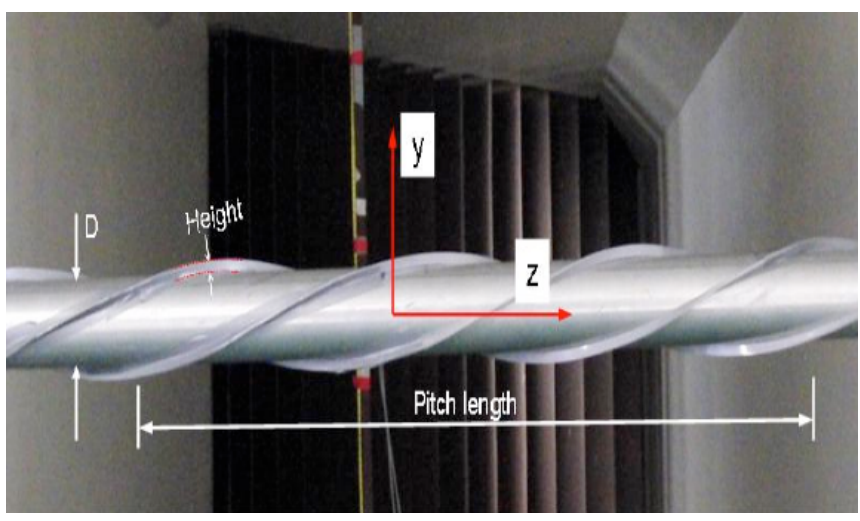

Fig. (1). Physical model of spiral strike strake cylinder.
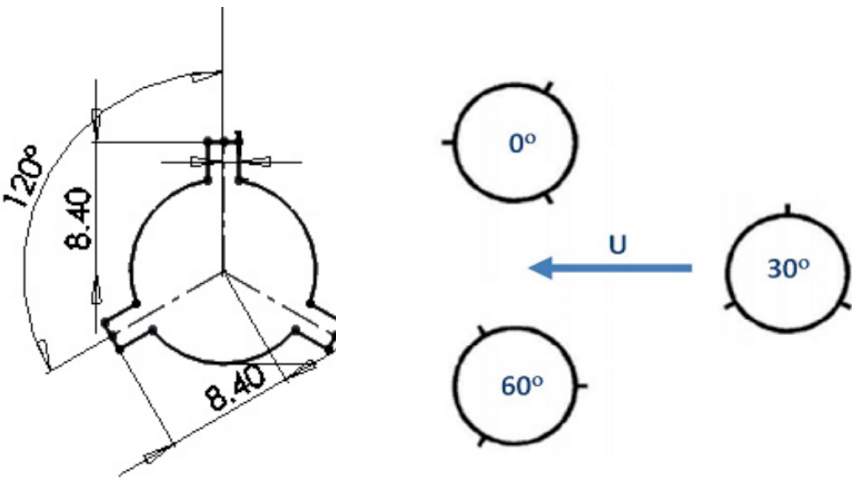

Fig. (2). Section (left) and incoming flow attack angle direction (right) of spiral strike strake cylinder, $\alpha=\left(0^{\circ}, 30^{\circ}, 60^{\circ}\right)$.
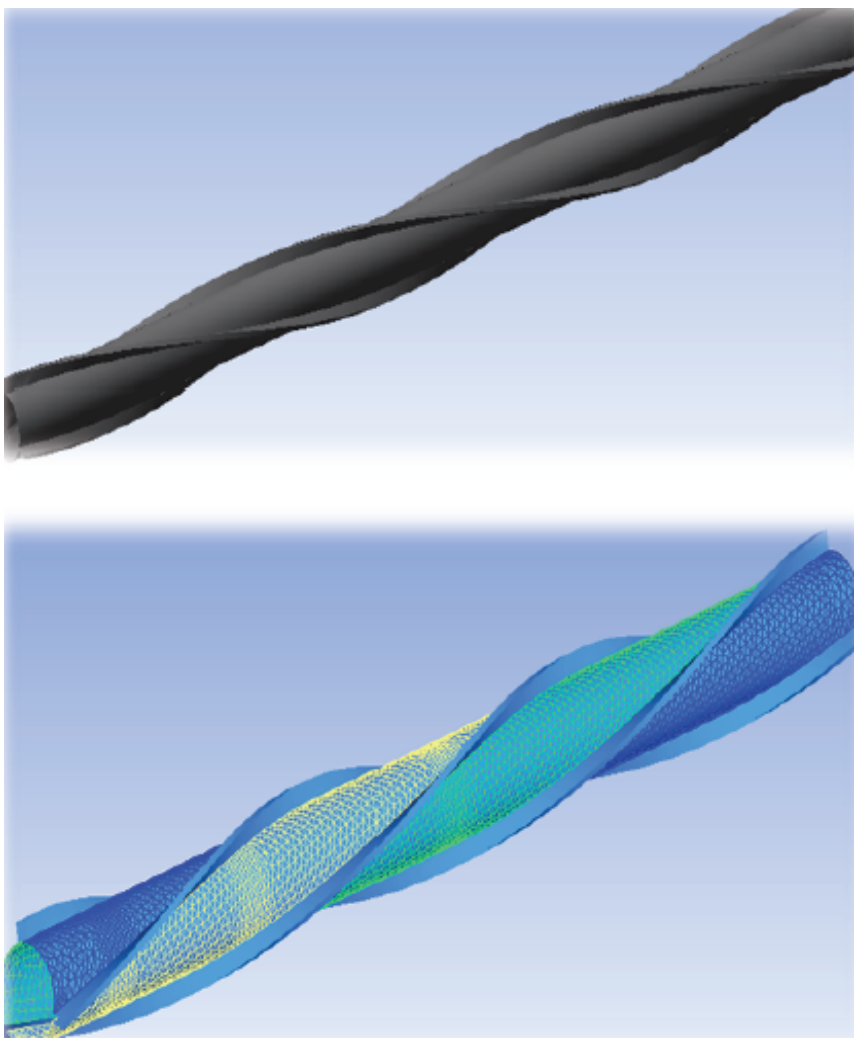

Fig. (3). Numerical model and surface grid of spiral strike strake cylinder. 


\section{ANALYSIS ON PVI SPEED FIELD AND VORTEX FIELD}

Fig. (4) shows the average speed vector $(U, V) U=0.6$ $\mathrm{m} / \mathrm{s}$ and $\alpha=30^{\circ}$ measured by PIV. The Figs. (4a-c) are the average speed vector diagrams. The heights of spiral strike strake are respectively $\mathrm{h}=0.1 \mathrm{D}(1.2 \mathrm{~mm})$ and $\mathrm{h}=0.2 \mathrm{D}(2.4$ $\mathrm{mm})$. The black flow line is also drawn on the diagram to display the fluid form. For the smooth cylinder wake flow, two symmetric loop flow areas are divided by the shear layer into two areas on both sides of the cylinder. The anticlockwise loop flow area is located at the up part and extends to the downstream till closed circulation. The clockwise loop flow area is located at the lower position at the downstream of the cylinder. For the strake height $h=1.2$ $\mathrm{mm}$ (Fig. 4b), the up and down loop flow areas are clear and visible and can be observed. Compared to the smooth cylinder, the downstream length of the loop flow area is increased. The average attachment point of the smooth cylinder occurs at about $-1.8 \mathrm{D}$. When the strake exists $(\mathrm{h}=$ $1.2 \mathrm{~mm}$ ). The average attachment point occurs at $-2.8 \mathrm{D}$. When the strake height is $\mathrm{h}=2.4 \mathrm{~mm}$ (Fig. 4c), it is obvious that the vector field is not symmetric along $\mathrm{y}=0$. The anticlockwise loop flow area above the center part is located at about $-1.8 \mathrm{D}$. The clockwise loop flow area is located at about $-2.5 \mathrm{D}$. For $\mathrm{h}=2.4 \mathrm{~mm}$, the flow length of this loop area increases and the average attachment point is located at about -4.5 D. Based on the above data, compared to the Fig. (4a), the vertical and horizontal length of the loop flow area of the Fig. (4b, c) increases and the average attachment point approximates to the cylinder. With increase of the strake height (Fig. $4 c), h=2.4 \mathrm{~mm}$ ), the loop area is not symmetric up and down. This phenomenon occurs because the valid diameter of the cylinder increases due to existence of the spiral strike strake, which changes conditions of the boundary layer and affects separation and falling of the shear layer from the cylinder wall. Change of the falling pattern of the shear layer can be observed in the Fig. (7) (instantaneous speed vector diagram and instantaneous vortex diagram). Change of the falling pattern of the shear layer disturbs the loop flow area around the wake flow area, vortex falling pattern and pressure field, so the orderly flow field and pressure field around the wake flow is disturbed till asymmetric state, which directly affects downstream vortex street falling and suppresses vortex-excited vibration to certain degree.

\subsection{Reynolds Stress Distribution}

The Fig. (5) shows the contour line diagram of the standard Reynolds stress $\left(\mathrm{U}=0.6 \mathrm{~m} / \mathrm{s}, \alpha=30^{\circ}\right)$. In fact, the solid line indicates the positive contour value and the broken line indicates negative contour value. The Figs. (5a-c) represent the smooth cylinder, the height $h$ of the spiral strike strake is $0.1 \mathrm{D}(1.2 \mathrm{~mm})$, and the height $\mathrm{h}$ of the strake is $0.2 \mathrm{D}(2.4 \mathrm{~mm})$. For the smooth cylinder and the cylinder with $1.2 \mathrm{~mm}$ strake, distribution of the standard Reynolds number is symmetric to the center. For the smooth cylinder, two additional small peak values $(0.01)$ occur around the wake flow of the cylinder. The maximum peak of the Reynolds stress shifts remotely. The Reynolds stress peak of the smooth cylinder occurs at about $-1.8 \mathrm{D}$. The peak of the (a)

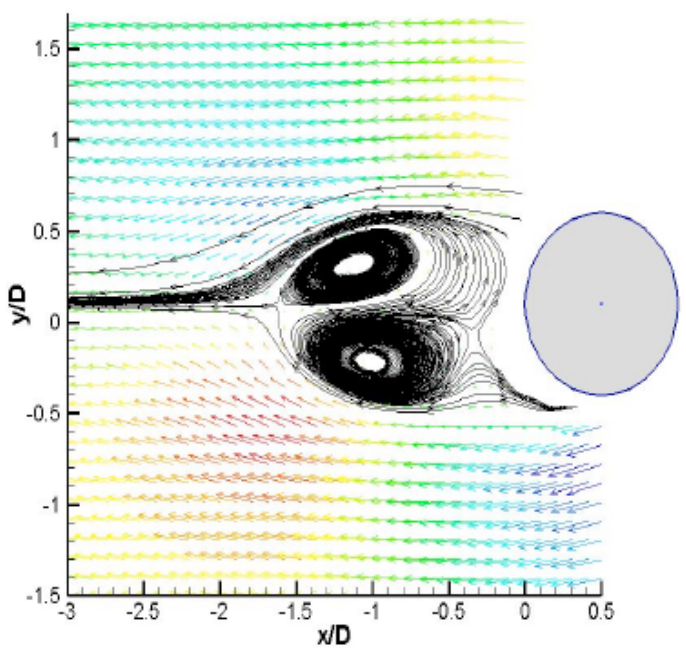

(b)

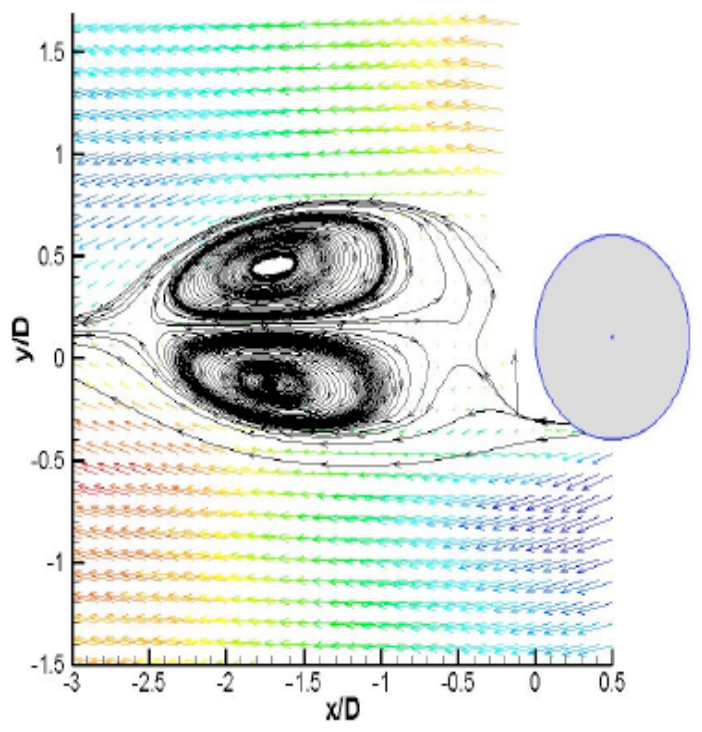

(c)

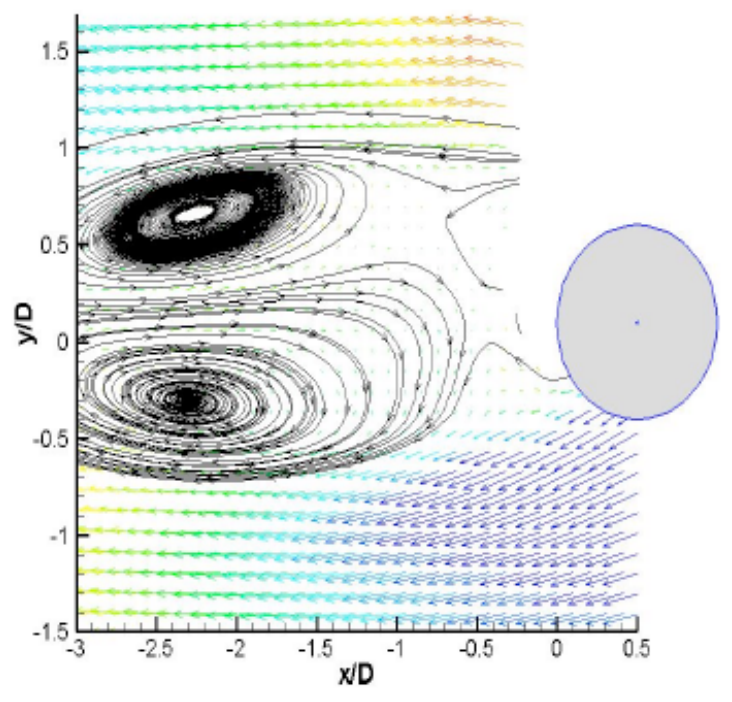

Fig. (4). Average speed vector diagram (U, V) $U=0.6 \mathrm{~m} / \mathrm{s}, \alpha=30^{\circ}$. (a) smooth cylinder; (b) h=0.1 D; (c) h=0.2 D. 
spiral strike strake $(\mathrm{h}=1.2 \mathrm{~mm})$ occurs at $-2.8 \mathrm{D}$. For $\mathrm{h}=2.4$ $\mathrm{mm}$, the peak shifts to $-3 \mathrm{D}$ point. The Reynolds stress for $\mathrm{h}$ $=2.4 \mathrm{~mm}$ should be non-uniform and asymmetric. The Fig. (5) indicates that the standard Reynolds stress of the spiral strike strake $(\mathrm{h}=2.4 \mathrm{~mm})$ reduces from 0.05 to 0.03 compared to the smooth cylinder.

(a)

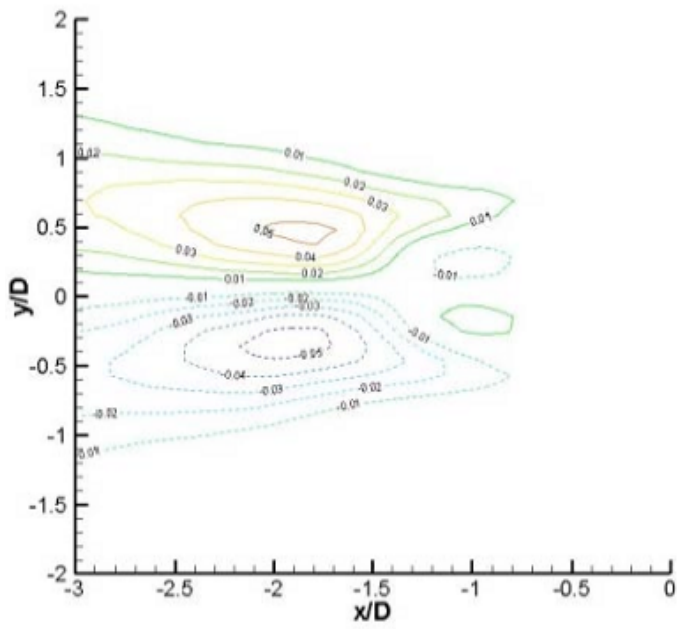

(b)

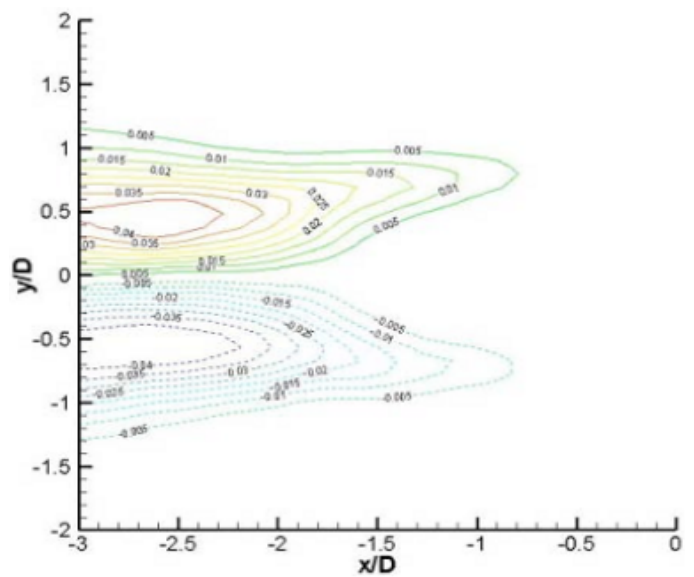

(c)

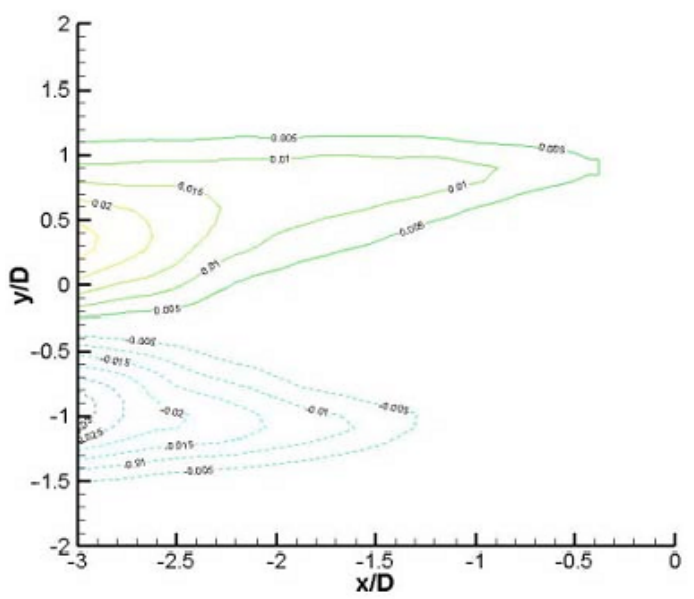

Fig. (5). Standard Reynolds stress contour line diagram, $U=0.6 \mathrm{~m} / \mathrm{s}$, $\alpha=30^{\circ}$. (a) Smooth cylinder; (b) h=0.1 D; (c) h=0.2 D.
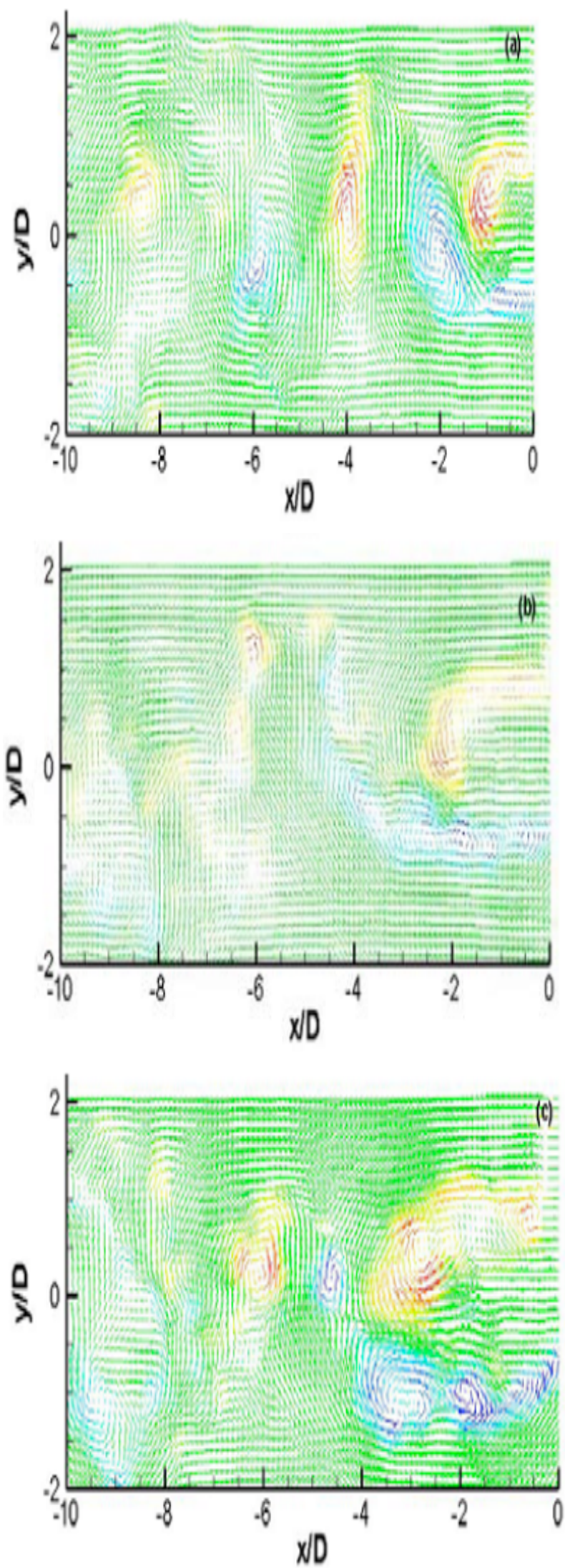

Fig. (6). Instantaneous speed vector diagram (U, V) $U=0.6 \mathrm{~m} / \mathrm{s}$, $\alpha=30^{\circ}$. 
(a)

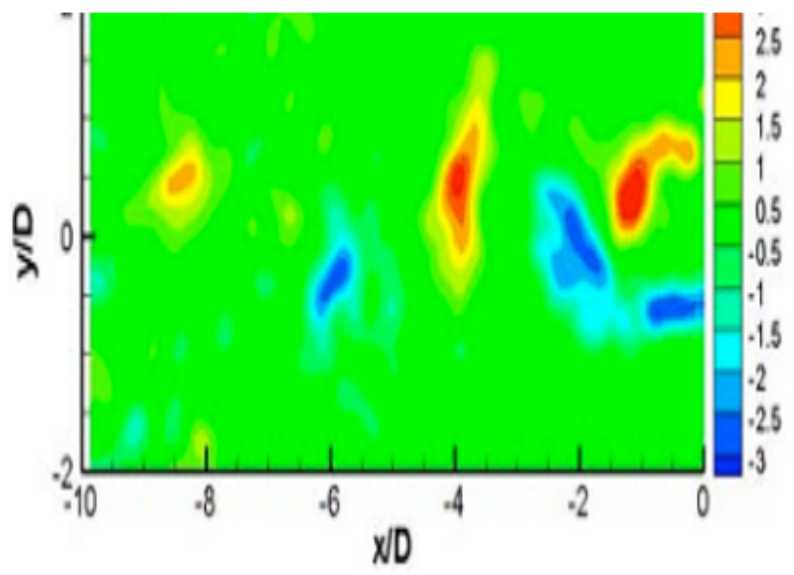

(b)

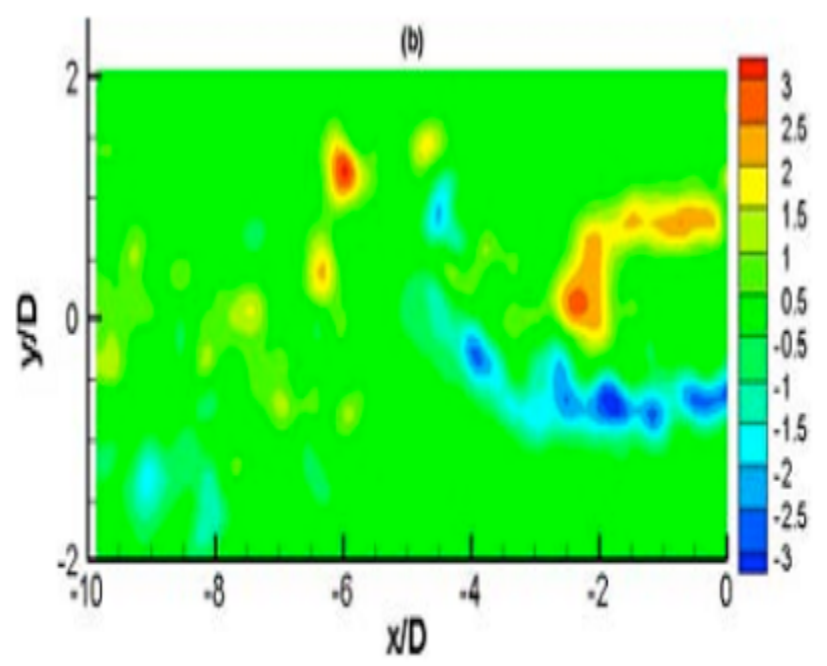

(c)

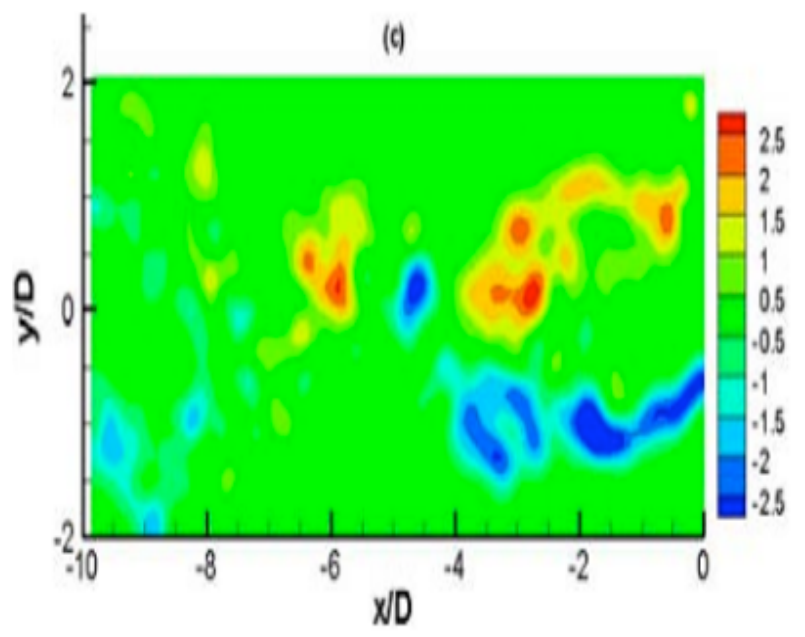

Fig. (7). Instantaneous vortex diagram (PIV results) $w_{z} D / U_{e}, \mathrm{U}=$ $0.6 \mathrm{~m} / \mathrm{s}, \alpha=30^{\circ}$. (a) Smooth cylinder; (b) h=0.1 D; (c) h=0.2 D.

To observe the average vector and Reynolds stress distribution, the influence of the spiral strike strake on instantaneous flow field and vortex street falling form can be observed. The Figs. $(\mathbf{6}, \mathbf{7})$ display the instantaneous speed vector diagram $(\mathrm{U}, \mathrm{V})$ and vortex diagram in wind extension direction (the reference speed is set as $0.5 \mathrm{Ue}$ ). In the Figs. $(\mathbf{5 a}, \mathbf{6 b})$, the up and down shear layer are mutually coiled up and penetrated into each other, which will drive regular pressure fluctuation at the boundary layer and further form the regular vortex falling in the wake flow area. The negative and positive vortex street in the centralized vortex area will alternatively occur and vibrate up and down around the symmetric center $(\mathrm{x} / \mathrm{D}=-2 \&-6$ indicates negative vortex and $\mathrm{x} / \mathrm{D}=0.5,-4,-8.2$ are the positive vortex). For the Figs. (5b, $\mathbf{5 c}, \mathbf{6 b}, \mathbf{6 c}$ ) of the spiral strike, although the wake flow vortex street is clear, but the spontaneous coupling of up and down shear layer will reduce much. The big vortex will break into continuous small vortexes and can't form the regular alternation of the negative and positive vortex street, so the regular vortex street falling can't be observed. Similarly, for the spiral strike strake, the big vortex structure will break into small vortex structure and the shear layer will stop coiling at downstream $\mathrm{x} / \mathrm{d}=-4$. The coupling of the shear layer will disappear, so it is predicted that the falling frequency of wake flow vortex street of the spiral strike cylinder will reduce much, even disappear.

\subsection{Research on Suppression Effect of Different Attack Angles}

The Fig. (8) shows instantaneous vortex diagrams of the strike strake wake flow field under three different attack angles. The attack angle is $\alpha=0^{\circ}, 30^{\circ}, 60^{\circ}$. The Fig. (8) indicates that different heights of the spiral strike strakes will have more significant disturbance on the wake flow field at the attack angle $\alpha=0^{\circ}$ compared to the attack angle $\alpha=30^{\circ}$ and $60^{\circ}$. When the attack angle $\alpha=0^{\circ}$ (referring to the Fig. 4), the effective disturbance diameter of the strike strake cylinder reaches the maximum. The strake is symmetric in the incoming flow direction. From the vortex diagram, the destruction capability of the strike strake to the vortex street seems to be weaker in case of $\alpha=60^{\circ}$. The front strake is parallel to the incoming flow direction in case of $\alpha=60^{\circ}$, which will weaken the disturbance of the front strake on the convection field. Only two strakes symmetric to the incoming flow direction close to the rear end will destruct the vortex street, so they will reduce influence of three-spiral strike strake on the vortex structure on the whole.

To further discuss destruction of the spiral strike strake on the wake flow vortex structure of the cylinder, this project performs the numerical simulation of the computing fluid dynamics (CFD) simultaneously. The instantaneous vortex diagram obtained by CFD (Fig. 9) indicates that existence of the spiral strike strake that destructs the winding vortex field of the cylinder in order to suppress the excited vibration. The higher the spiral strike strake screw, the stronger the destruction effect of the vortex structure is, which is consistent with the phenomenon observed in PIV experiment. The Figs. $(\mathbf{6}, 7)$ are the instantaneous vortex diagrams. The instantaneous vortex fields of two diagrams are not comparable to each other in detail due to instantaneous time choice uncertainty in the experiment and simulation. However, in the Figs. $(6,7)$, the non-normalized vortex strength amplitude $\left(w_{z} D / U_{e}\right)$ and vortex street falling form are still very comparable (the amplitude is between $3 \sim 3)$. From the Figs. (7a, 9a), the regular vortex street falling can be observed. With the growth of the strake height (Figs. 
$(7 \mathbf{b}, \mathbf{c}, \mathbf{9 b}, \mathbf{c})$, the shear layer is separated from the cylinder wall surface and the vortex street falling is disturbed much by the spiral strike. The mutual interaction interval of the up and down shear layer and vortex (clockwise and anticlockwise) of the wake flow becomes big and the cycle becomes longer. The suppression effect of the vortex-excited vibration becomes more significant.

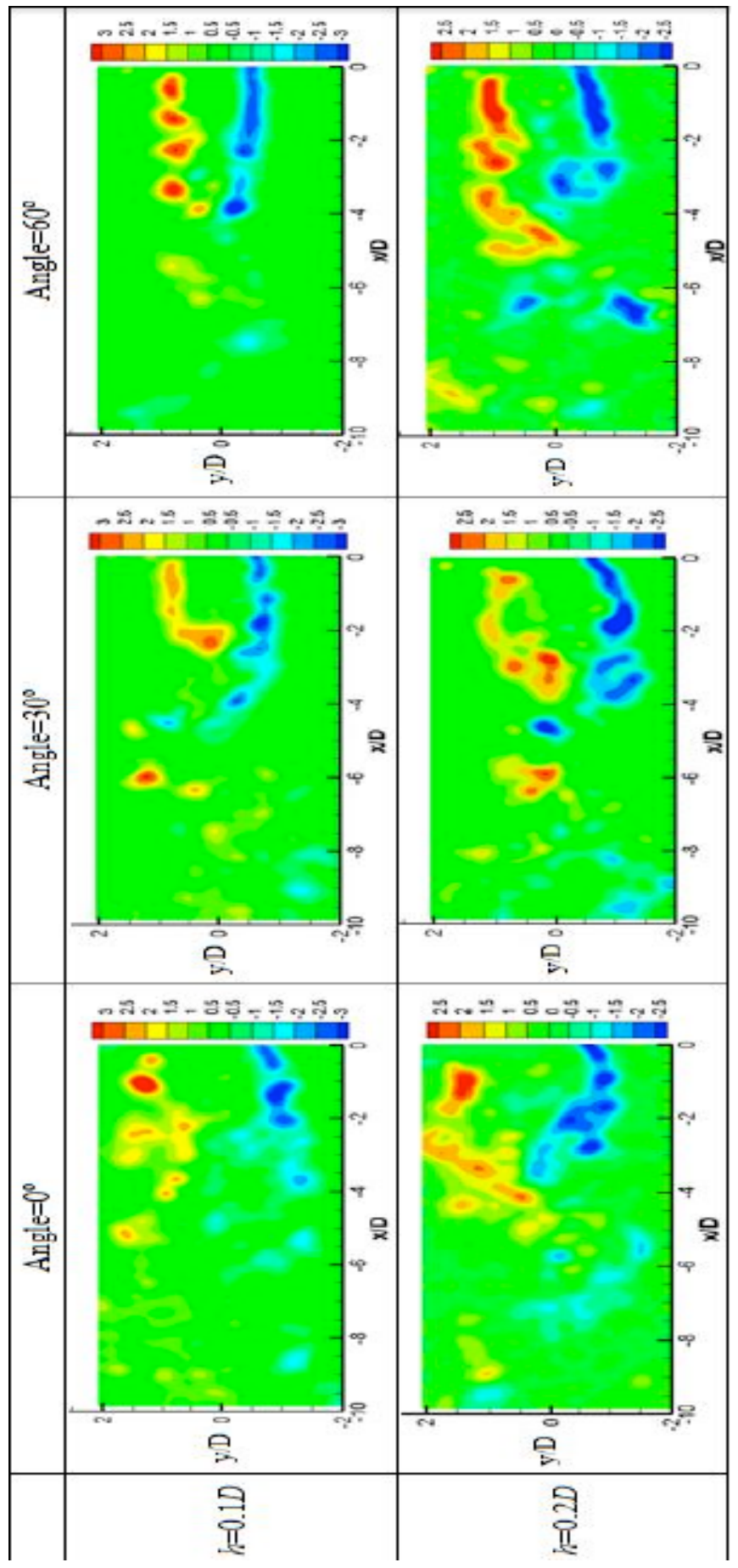

Fig. (8). Instantaneous vortex diagram $w_{z} D / U_{e}$ under three different attack angels, $\mathrm{U}=0.6 \mathrm{~m} / \mathrm{s}, \alpha=0^{\circ}, 30^{\circ}, 60^{\circ}$. (a)

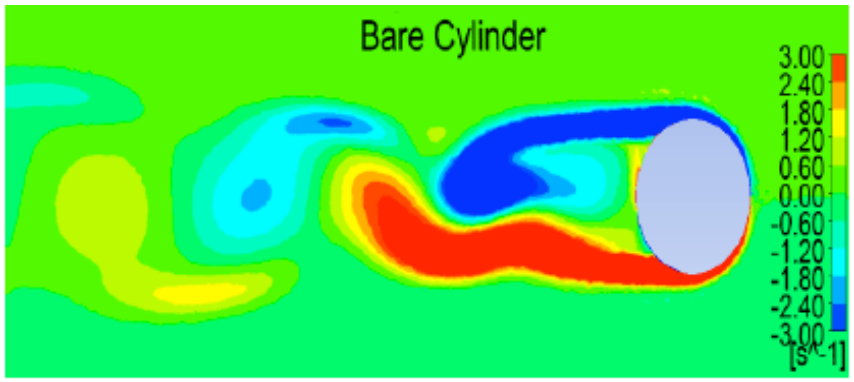

(b)
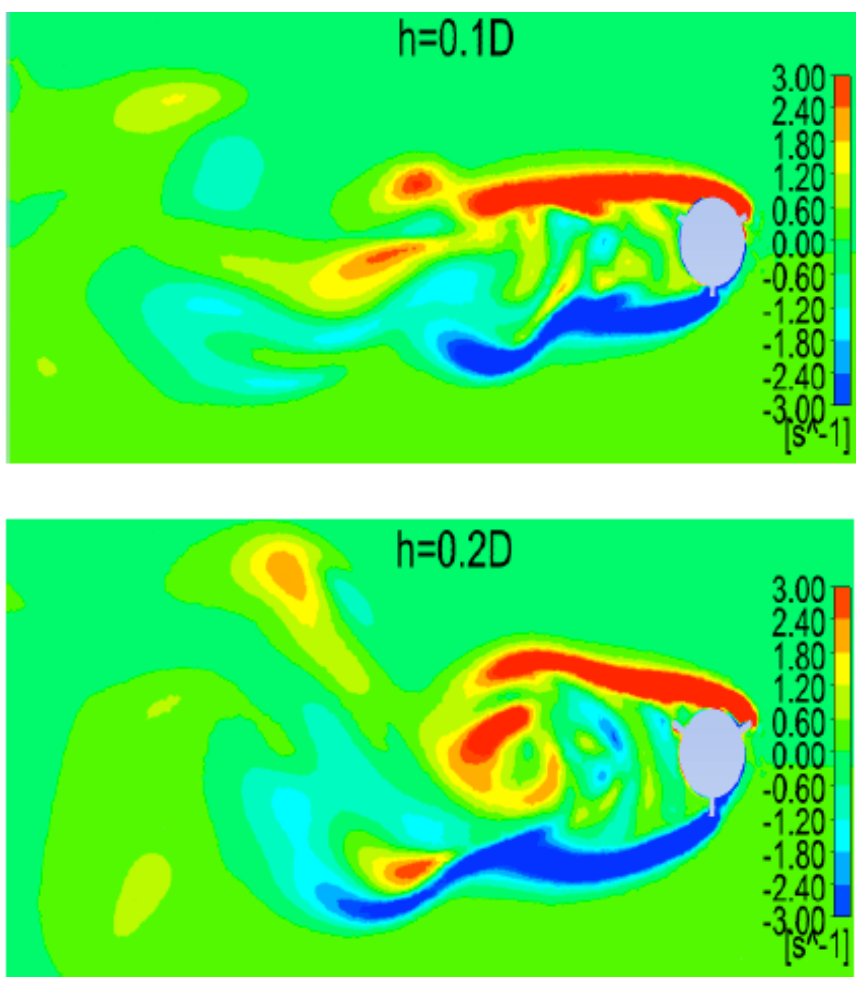

Fig. (9). Instantaneous vortex diagram (CFD) $w_{z} D / U_{e}, U=0.6 \mathrm{~m} / \mathrm{s}$, $\alpha=30^{\circ}$. (a) Smooth cylinder: (b) $\mathrm{h}=0.1 \mathrm{D}$; (c) $\mathrm{h}=0.2 \mathrm{D}$.

\section{EXPERIMENTAL CONCLUSION}

This paper carries out experimental research and analysis on the vortex-excited vibration suppression effect of the spiral strike strake by using PIV when the incoming flow speed $U$ is $0.6 \mathrm{~m} / \mathrm{s}$ and the attack angle is $\alpha=300$. Also it discusses the suppression mechanism of the VIV suppression mechanism of the spiral strike strake by using the numerical simulation of computing fluid dynamics (CFD). The results display that the spiral strike strake significantly affects formation of the boundary layer and shear layer, falling form of wake flow vortex, and destructs regular negative and positive vortex street alternation, so it further suppresses the regular vortex falling and the vortex-excited vibration. Under the experimental conditions, when the spiral strike height $h$ is $0.2 \mathrm{D}$, the suppression effect of the vortex-excited vibration is better than that of the strake $(\mathrm{h}=0.1 \mathrm{D})$ and the strake 
has bigger disturbance on the wake flow. The instantaneous vortex contour diagram in the wind extension direction and the instantaneous speed vector indicate that the shear layer stops coiling at $\mathrm{x} / \mathrm{d}=4$ downstream point from the cylinder and gradually increases till the vortex structure breaks into the small vortex structure in case of the spiral strike strake. To compare the instantaneous vortex diagram under three different attack angles, for different spiral strake heights, the disturbance on the wake flow field is the most significant in case of $\alpha=0^{\circ}$. The destruction effect on the vortex street is minimal in case of $\alpha=60^{\circ}$. The instantaneous vortex diagram obtained by CFD indicates that spiral strike strake destructs the winding vortex field of the cylinder, so it can suppress the vortex-excited vibration. The higher the spiral strike strake screw, the stronger the destruction effect of the vortex structure is, which is consistent with the phenomenon observed in PIV experiment.

\section{CONFLICT OF INTEREST}

The author confirms that this article content has no conflict of interest.

\section{ACKNOWLEDGEMENTS}

Declared none.

\section{REFERENCES}

[1] X.G. Song, L. Can, and H. Zhang, ANSYS flow solid coupling analysis and engineering instance. Chinese science bulletin, Water Conservancy and Hydroelectricity Press, 2014.

[2] X.C. Wang, Finite Unit Method. Beijing: Tsinghua University Press, 2003.

[3] P. Bearman and M. Branković, "Experimental studies of passive control of vortex-induced vibration", European Journal of Mechanics B/Fluids, vol. 23, pp. 9-15, 2004.

[4] Y. Constantinides and O.H. Oakley, "Numerical prediction of bare and straked cylinder VIV", In: Proceedings of 25th International Conference on Offshore Mechanics and Arctic Engineering, June, Hamburg, Germany: IEEE, pp.4-9, 2006.

[5] Z.L. Liu, "Fractal theory and application in city size distribution", Information Technology Journals, vol. 12, no. 17, pp. 4158-4162, 2013. R.A. Kumar, C.H. Sohn, and H.L. Gowda, "Passive control of vortex-induced vibration: an overview", Recent Patents on Mechanical Engineering, vol. 1, pp. 1-11, 2008.

[6] G. Godard and M. Stanislas, "Flow control APG boundary layer vortex generators PIV", Aerospace Science and Technology, vol. 10, pp. 181-191, 2006. 